\title{
Erratum to: Macroprudential consolidation policy in interbank networks
}

\author{
E. Gaffeo ${ }^{1}$ - M. Molinari ${ }^{2}$
}

Published online: 22 March 2016

(C) Springer-Verlag Berlin Heidelberg 2016

\section{Erratum to: J Evol Econ (2016) 26:77-99 \\ DOI 10.1007/s00191-015-0419-3}

The html version of this paper includes a mistake. The first instance of the below reference:

Gaffeo E, Molinari M (2015) Interbank contagion and resolution procedures: inspecting the mechanism. Quant Finance 15(4): 637-652 should be:

Gaffeo E, Molinari M (2014). Macroprudential consolidation policy in interbank networks. DEMWorking Paper 2014/1, University of Trento

The online version of the original article can be found at http://dx.doi.org/10.1007/s00191-015-0419-3.

\section{Molinari}

massimo.molinari@uniroma1.it

E. Gaffeo

edoardo.gaffeo@unitn.it

1 Department of Economics and Management, University of Trento, Via Inama 5, I-38100 Trento, Italy

2 Department of Economics and Law, Sapienza University of Rome, Via del Castro Laurenziano 9, 00161 Rome, Italy 